\title{
Assessing Public Awareness and use of the Freedom of Information (FOI) Act: A study of Port Harcourt City
}

Aniefiok Udoudo*, Christopher Ochonogor \& Daniel Nwanmereni

Department of Linguistics and Communication Studies, University of Port Harcourt, Nigeria

DOI: $10.36347 /$ sjahss.2020.v08i01.006

| Received: 27.12.2019 | Accepted: 04.01.2020 | Published: 18.01.2020

*Corresponding author: Aniefiok Udoudo

\section{Abstract}

Original Research Article

The enactment of the Freedom of Information (FOI) Act in Nigeria in 2011 elicited wide acceptance not only among civil society organisations but also members of the public who agitated for the passage of the FOI bill while it underwent legislative process. Such agitations were rife since it was thought that the legislation would guarantee Nigerian citizens unbridled access to official records as well as participation in the governance of the country. This study investigated the extent of awareness and use of the FOI Act by Port Harcourt residents. The study, among others, addressed the following research questions: To what extent are Port Harcourt residents aware of the Freedom of Information (FOI) Act? What is the extent of use of the Freedom of Information (FOI) Act by Port Harcourt residents? The investigation adopted survey research design to study a population of 199, 583 from which a sample size of 383 respondents was drawn. Findings of the study showed a substantial high awareness but low application of the FOI Act among Port Harcourt residents. The study also found out that the agencies which spearheaded the passage of the FOI bill into an Act have not done much to sensitise citizens of Nigeria on the usefulness of the Act. The study recommended, among other things, that civil society organisations should initiate nationwide public enlightenment programmes to sensitise Nigerians on the contents and value of the FOI Act.

Keywords: Freedom of Information; Nigeria's Freedom of Information (FOI) Act; Port Harcourt Residents; Awareness of the FOI Act; Use of the FOI Act.

Copyright @ 2020: This is an open-access article distributed under the terms of the Creative Commons Attribution license which permits unrestricted use, distribution, and reproduction in any medium for non-commercial use (NonCommercial, or CC-BY-NC) provided the original author and source are credited.

\section{INTRODUCTION}

The struggle for freedom for members of the human community became enhanced following the Universal Declaration of Human Rights by the United Nations (UN) General Assembly on December 10, 1948. This declaration guarantees the inherent dignity, equal and inalienable rights of all humans across the world. The Assembly held that the Declaration is a common standard of achievement for all peoples and all nations to the end that every individual or organ of the society, keeping the declaration constantly in mind, shall strive by teaching and educating to promote respect for the rights and freedoms enshrined in the declaration. The provisions of this Declaration as well as those of other human rights charters, such as the European Covenant on Human Rights of 1953, the American Convention on Human Rights of 1978 and the African Charter on Human and People's Rights of 1986 impress it upon many countries of the world to integrate and entrench freedom of expression not only in their constitutions but also in other legal frameworks [1]. The essence of the formulation of such legal instruments is the creation of a safe atmosphere within which members of the public can air their views as well as have freer access to requisite information.

Nigeria, apart from being a signatory to some of these charters and conventions, guarantees freedom of expression for its citizens in Section 39 of the 1999 Constitution. The provisions of this section of the Nigerian Constitution is gratifying, but the growing culture of impunity, indiscipline, inefficiency and official secrecy in the country's public and private sectors became a major source of worry for some interest groups and the Nigerian masses. The promulgation of some laws, such as the Official Secrets Act and some sections of the Criminal Code, for instance, not only aided but also provided legal effect to the culture of official secrecy in Nigeria. This condition necessitated the quest for a legal instrument to guarantee citizens more access to official information and records. This quest, which was spearheaded by the Media Rights Agenda (MRA), culminated in the enactment of Nigeria's Freedom of Information (FOI) Act in 2011; to provide members of the Nigerian public 
access to official information and promote transparency, accountability and good governance in the country.

The focus of the Freedom of Information Act, according to Ashong and Udoudo [2], is to overcome the shortcomings of Section 39 of Nigeria's 1999 Constitution. It is to provide members of the Nigerian public with a legal instrument guaranteeing access to official information and records which would not be superseded by the Official Secrets Act or any other law. The Nigerian Freedom of Information bill was signed into law on May 28, 2011. Having got the Act enacted, it is now left for the citizens to take advantage of it to advance the due process which the law seeks: to bring about a better Nigerian society.

\section{Statement of the Problem}

The delay the Freedom of Information (FOI) bill witnessed while it underwent legislative process was characterised by wide outcries by members of the Nigerian society who agitated and longed for its passage. The reason for such agitations was borne out of the expected end to official secrecy and a secured access to official information and records which the bill was to provide when passed into law. It was thought that the bill would grant members of the Nigerian public the right to seek and obtain information and records which were either scarcely available or utterly withheld from the public due to the existence of the Official Secrets Act which legitimised official secrecy in both public and private sectors. These agitations by the Nigerian masses, civil society coalition and the mass media resulted in the popularisation of the FOI bill and the wide acceptance it elicited when it was eventually signed into law by President Goodluck Jonathan in May, 2011.

Having the FOI bill passed into law, one would have expected Nigerian citizens to obtain and use official information hitherto classified as secrets for the purpose of transparency. Indeed, it was expected that members of the Nigerian society would have aggressively used the FOI Act to pursue due process, uncover crimes and confront alleged corrupt practices in both public and private sectors of the Nigerian economy. The burden is that, irrespective of the FOI Act guaranteeing people's access to official information and records, members of the Nigerian public seem oblivious of the Act. It appears the fervour with which members of the public agitated for the passage of the bill has not been translated into action. Is it because members of the public are not aware of the provisions of the Freedom of Information Act? This is the concern that this study seeks to address.

\section{OBJECTIVES OF THE STUDY}

The objectives of the study were to:

- Find out the extent of awareness of the Freedom of Information Act among Port Harcourt residents;
- Ascertain the extent of use of the Freedom of Information Act by Port Harcourt residents; and

- Ascertain the factors militating against the application of the Freedom of Information Act by Port Harcourt residents.

\section{Definition of Terms}

The definition of the following terms was based on their usage within the context of this work and not the lexical meanings:

Extent of Awareness: This implies the extent to which Port Harcourt residents are aware of the Freedom of Information (FOI) Act. The extent of awareness of the FOI Act will be measured by the number of respondents who have knowledge of the contents of the FOI Act and not merely the awareness of the existence of the Act.

Extent of Use: By extent of use, we mean the extent to which Port Harcourt residents have used the FOI Act to seek official information. The parameter for assessing the extent of use of the FOI Act is the number of respondents who have actually used the Act in seeking official records or information.

Port Harcourt Residents: Port Harcourt Local Government Area is one of the Local Government Areas in Rivers State. This study is concerned with all residents of the Local Government Area from 18 years and above.

\section{LITERATURE REVIEW \\ Uncertainty Reduction Theory}

Uncertainty reduction theory focuses on how human communication is used to gain knowledge and create understanding. Griffin [3] states that Charles Berger - a professor of communication at the University of California, who is credited with this theory, postulates that social relationships are fraught with uncertainties owing to the existence of suspicion. This calls for the establishment of a free flow of information towards achieving understanding among interacting groups. This is essentially because humans become prone to taking certain actions which could be detrimental to them in the event of a lack of access to basic information which would have formed the basis for undertaking such actions. Griffin [3] thus argues that "reducing cognitive uncertainty means acquiring information that allows you to discard many of these possibilities" (p. 137). Such possibilities, as stated earlier, include undertaking actions that could rather become counter-productive.

The Uncertainty reduction theory conceives humans are intuitive psychologists. They become inventive at given circumstances, especially in the event of lack of access to some basic needs, one of which is the poverty of information. When people are provided with requisite information, they become empowered to make informed decisions on issues. It also means that 
when people are not informed, they could become gullible. This could create avoidable uncertainties or conflicts in the society.

\section{Freedom}

Freedom is the right to own oneself. It is the right to act, live and speak freely. According to Locke [4], cited in Bhargava and Ashok [5], freedom is the "inalienable right of man" (p. 43). It is the right of individual members of any given society, in accordance with the law, to choose the pattern of existence that serves and suits their interest. Thus, Bhargava and Ashok [5] state that freedom is the ability to do what the law of nature allows. That is, doing what is morally permitted.

The foregoing view of freedom is opposed to what obtained in the evolution of societies, especially during the absolutist era. During this era, the rights of ordinary members of the public were denied them by the monarchs. Nwodu [6] observes that most traditional societies were governed by monarchs. These monarchs were more of demi-gods whose words were laws and hardly challenged by their subjects. While the monarchs ruled as the representatives of God who could do no wrongs, the ordinary people were considered base elements who lacked reason to contribute to rational discourse. It was an offence during this era to express ideas and thoughts freely. In other words, freedom of expression was not guaranteed. Daramola [7] states that during this era, it was only the pope that had access to the Holy Bible, which was misinterpreted as not supporting freedom of expression.

As time went on, however, people became unsympathetic to the state of affairs at that time. People pressured for freedom to ventilate their views and access to the day's intelligence (at least, an access to the Holy Bible and the press). These agitations led to the persecution of some of the critics of the monarchs and the elite. While some of the agitators were executed, others were banished [7]. But these penalties could not abate people's clamour for freedom. People continued to agitate for a freer and democratised society where citizens have rights to freedom of expression. Also, these agitators demanded that the possession of the means of communication should depend upon one's ability to do so and not membership of the royal family or of the ruling class. In the view of these agitators, the state should be the provider, protector and enforcer of the rights of the citizens and not the imposer of restriction to natural laws, such as the freedom to express oneself. Johari [8] argues that:

Freedom is the provision of rights with their due enforcement by the state that ensures freedom to a citizen and thereby enables him to seek the best possible development of his personality. The purpose of the state is not confined merely to the maintenance of law and order, or protection of the weak against the strong; it is also concerned with the creation and preservation of that atmosphere in which an individual has every opportunity to sharpen his constructive initiative (p. 252).

Johari [8] maintains that freedom "means the absence of constraints and not the absence of restraints and limitations. It does embrace an area of man's choice, and at the same time, calls for the proper justification of the limits or restrictions on such an area (p. 252). The implication of this is that though freedom should not be absolute, the limit of freedom of members of the society must be governed by justifiable reasons. Freedom must be exercised with responsibility, as the absence of this precipitates anarchy. Johari [8] adds that "the condition of being able to be free does not imply that a man may do something wrong so as to convert his freedom into a state of unfreedom" (p. 254). This gives legitimacy to the view earlier espoused by Mill [9] that the reason humans are warranted (individually or collectively) to interfere with the liberty of action of any individual is the protection of others.

\section{INFORMATION}

Information is a veritable and indispensable ingredient necessary for the survival of humans in their environment. To be informed is to be acquainted with the knowledge of an event or occurrence. Information provides knowledge, caution and direction. With this knowledge, individuals and groups engage in activities or take decisions necessary for the well-being of their society. It enables people to take decisions that serve their best interest. Thus, Asadu and Usua [10] observe that information provides knowledge and with knowledge, humans derive understanding which can lead to socio-political, economic and cultural actions. This implies that the decisions people make at given circumstances are the functions of the nature and quality of information at their disposal. Dysfunctional and irrational decisions, to some extent, are consequences of ignorance or misinformation. To this end, an ill-informed or ignorant person could be misguided.

UNESCO [11] stipulates that information remains a basic requirement for individuals, organisations, the media, agencies, schools, institutions of learning, governments and other firms in the course of their daily activities. UNESCO further argues that "if the exchange of information becomes ample, misleading descriptions would be outweighed by those which are genuinely enlightening" (p. 184). It is evident that the flow of technical information within nations and across national frontiers is a major resource for development. Smith [12] states that "providing people with quality information is one of the keys to helping them to develop their independence" (p.47). It goes to say that access to useful information serves as a psychological security net which prevents individuals 
from undertaking actions that could be inimical to them or to other members of their environment.

Article 19 [13] offers that the other side of freedom of expression is the right to information. This, Article 19 maintains, is based on the premises that information is the oxygen of democracy. It is essential for openness, accountability and good governance. According to Article 19 [13], information:

- Enables people to have informed opinions and to engage in full and open debates;

- Ensures governments are scrutinised, thereby becoming more open, transparent and accountable and delivering good governance;

- Enables elections to be free and fair by informing the electorate;

- Enables journalists and civil society to expose corruption and wrong doing;

- Enables people to access their own personal information, a valuable part of respecting basic human dignity;

- Enables people to make effective personal decisions, such as in medical treatment or financial planning;

- Facilitates the effective business practices by creating culture of bureaucratic openness and providing information that can be useful for enterprise.

The provision and exchange of requisite information help to motivate a target population to abandon certain alien practices to embrace improved ideas and methods. It mobilises people and cultivates their willingness and support for a well-defined goal. This helps to foster participation, mutual cohesion and involvement which creates an atmosphere of progress and stability.

\section{Nigeria's Freedom of Information (FOI) Act}

Nigeria's Freedom of Information Act, otherwise known as the Freedom of Information Act 2011, is an act of the National Assembly which empowers members of the Nigerian public to seek and obtain information and records in the custody of both public and private authorities in the country. The Act provides members of the public more access to official records and information, to promote transparency and accountability in both public and private sectors of the Nigerian economy. It was enacted to overcome the culture of official secrecy which was legitimised by the Official Secrets Act. Anyanwu, Akanwa and Oyemike [14] observe that prior to the enactment of the Freedom of Information Act, almost all government information in Nigeria were classified top secret. This situation made it difficult for citizens to obtain information from the government and other agencies.

Nigeria's Freedom of Information states that:

Notwithstanding, contained in any other act, law or regulation, the right to any person to access or request information, whether or not contained in any written form, which is in the custody or possession of any public official, agency or institution howsoever described, is hereby established (p. 3).

This Act not only guarantees access to records and information but also defines the superiority of the Freedom of Information Act over other laws that are antithetical.

In the event of the refusal of access to official records by any public or private organisation, Sections 2 (3) and 3 (6) of the FOI Act provide that any person denied access to certain information, the right of which is provided in the Freedom of Information Act, holds the right to institute proceedings in court to compel the concerned public or private organisation to comply with the provision of this Section. According to Section 3 (7) of the Act, the obligation for the provision of information to members of the Nigerian public is binding on all public institutions whether executive, legislative or judicial, ministries and extra-ministerial departments of the government, together with all corporations established by law and all companies in which government has a controlling interest, also private companies utilising public funds, providing public services or performing public functions.

Clearly defining protection for disclosure of information, the foregoing section provides that a public official can disclose any information which he believes will reveal:

- A violation of any law, rule or regulation;

- Mismanagement, gross waste of funds, fraud and abuse of authority; or

- A substantial and specific danger to public health or safety notwithstanding that such information was not disclosed pursuant to the provision of the Act.

The main focus of Nigeria's Freedom of Information Act, as noted by Ashong and Udoudo [2], is to promote transparency and accountability in both public and private sectors of the economy. The implementation of the Act to accomplishing the purposes for which it was enacted will require the sincerity of the government and private authorities in making records in their custody accessible. It also requires the willingness of members of the public to seek such records.

\section{METHODOLOGY}

The research design adopted to carry out this study was descriptive survey. Survey provided the room to uncover respondents' extent of the knowledge, view and attitude towards the FOI Act. The population of this study comprised male and female adult residents of Port Harcourt City Local Government Area (18 years and above). The population of adult residents (20 years and 
above) in Port Harcourt was 198,787. This figure is about $36.73 \%$ of the 541, 115 population figure of Port Harcourt published in the 2006 Population Census exercise [15]. An annual population increase of about $2.5 \%$ (between 2007-2018) brought the study population to 199,585 .

A total of 383 formed the sample size for the study. This sample size was based on Keyton's sampling system [16]. The study adopted the probability sampling system, using the systematic sampling technique. Data were collected through the questionnaire. Data presentation was done in statistical tables using simple percentages

\section{Data Presentation}

To generate data for the study, 383 copies of the questionnaire were administered on the sample of the study. Out of this number, 377 copies were returned, giving a return rate of $98.43 \%$. Only six copies were not returned. However, of the copies returned, five $(1.32 \%)$ copies were wrongly filled and not useful for analysis. The data presentation was based on the $372(97.12 \%)$ copies of the questionnaire which were properly filled and returned.

Table-1: Respondents' extent of awareness of the FOI Act

\begin{tabular}{|l|l|l|}
\hline Awareness & No. of Respondents & Percentage \\
\hline Aware of the FOI Act to a large extent & 263 & 55.11 \\
\hline Awareness of the FOI Act by its existence & 88 & 23.66 \\
\hline Not aware of the FOI Act & 21 & 21.23 \\
\hline Total & 372 & 100 \\
\hline
\end{tabular}

Regarding respondents' level of awareness of the FOI Act, data presented in Table-1 indicated that many residents of Port Harcourt City were aware of the FOI Act.

Table-2: Awareness of the process of using the FOI Act to seek official information

\begin{tabular}{|l|l|l|}
\hline Awareness & No. of Respondents & Percentage \\
\hline Awareness of the process of applying the FOI Act & 341 & 62.28 \\
\hline Not aware of the process of applying the Act & 31 & 37.72 \\
\hline Total & 372 & 100 \\
\hline
\end{tabular}
information.

Data presented in Table-2 show that many Port Harcourt residents knew how to use the FOI Act to obtain

Table-3: Use of the FOI Act

\begin{tabular}{|l|l|l|}
\hline Responses & No. of Respondents & Percentage \\
\hline I have obtained an official record with the FOI Act & 36 & 3.59 \\
\hline $\begin{array}{l}\text { I was not allowed access to the official record I } \\
\text { requested even with the FOI Act in place }\end{array}$ & 11 & 5.39 \\
\hline Yet to use the Act to seek official records & 325 & 86.83 \\
\hline Total & 372 & 100 \\
\hline
\end{tabular}

Data presented in Table-3 indicate that many residents of Port Harcourt were yet to use the FOI Act to seek access to official information.

Table-4: Constraints to the application of the FOI Act by Port Harcourt residents

\begin{tabular}{|l|l|l|}
\hline Constraints & No. of Respondents & Percentage \\
\hline Not aware of the contents/ provisions of the FOI Act & 33 & 7.78 \\
\hline Fear of victimisation by authorities & 170 & 6.58 \\
\hline Prevailing culture of official secrecy despite the FOI Act & 67 & 5.39 \\
\hline Lack of motivation by relevant agencies & 102 & 4.19 \\
\hline Total & 372 & 100 \\
\hline
\end{tabular}

Regarding constraints to the effective implementation of the FOI Act, Table- 4 shows that many residents of Port Harcourt were yet to use the FOI Act due to fear of victimisation by authorities. The Table also shows that the effort made by civil society organisations towards the enactment of the FOI Act is yet to be replicated to sensitise members of the public to use the Act to seek access to official information.

\section{DISCUSSION OF FINDINGS}

The discussion was based on the research questions set for the study. 
Research Question 1: To what extent are Port Harcourt residents aware of the Freedom of Information (FOI) Act?

Responses regarding this research question indicated a substantial high awareness of the FOI Act by Port Harcourt residents. This is evident from 263 $(55.11 \%)$ respondents who were aware of the FOI Act to a large extent (Table-1). Obviously, the high level of awareness of the Freedom of Information Act among Port Harcourt residents is not surprising, especially due to the popularisation of the FOI bill while it underwent legislation. The awareness of the FOI Act by members of the Nigerian public due to the popularisation of the bill that established the Act exemplifies the importance of information in empowering the populace. Berger's Uncertainty Reduction Theory identifies the importance of information in the management of the society. Smith [12] argues that providing citizens access to information is one of the way to enlarge their independence.

\section{Research Question 2: What is the extent of use of the Freedom of Information (FOI) Act by Port Harcourt residents?}

Data presented in Table-2 indicate a gross under-utilisation of the FOI Act by Port Harcourt residents. The argument is that if only 36 (3.59\%) respondents among those who were aware of the FOI Act (especially those who have knowledge of the contents of the Act) have actually utilised it to seek official records, then the application of the FOI Act among Port Harcourt residents is substantially low.

That only a limited number of Port Harcourt residents who were aware of the FOI Act had requested access to official information/ records does not represent commitment towards the implementation of the Act. It is instructive to emphasise that the enactment of the FOI Act does not imply that seekers of official information/ records would not encounter opposition from both private and public organisations in the country or officers who have custody of records. The FOI Act, as a matter of fact, envisaged such oppositions and has made provisions for those whose requests to official information could be refused to seek redress in courts (Freedom of Information Act, 2011) [17]. Under the provisions of the FOI Act, the judiciary is charged with the mandate to compel erring organisations and institutions to respect the FOI Act or face stipulated penalties, except the records being sought fall within the exempted matters which members of the public may not access.

\section{Research Question 3: What are the factors militating against the application of the Freedom of Information (FOI) Act by Port Harcourt residents?}

One of the critical constraints to the effective utilisation of the FOI Act identified by the respondents was fear of victimisation. Another crucial constraint to the implementation of the FOI Act as identified by the respondents is the lukewarm attitude most members of the public exhibit towards issues of public concern. Everybody craves for a better society but not everybody dares to pursue due process. The lackluster attitude to the utilisation of the FOI Act by members of the public is perhaps the offshoot of the experiences which characterised the pre-Freedom of Information era in Nigeria when citizens' access to official records was greatly restricted. Gibson [18] observes that one of the most difficult challenges facing transition is the problem of the past. Since Nigeria has had eras during which access to official information/records was greatly restricted with the promulgation of some stringent decrees and public officers were punished for divulging information to members of the public and journalists, it appears that people still live with the apprehension of the past. This apprehension seems to be currently taking a significant toll on the effective implementation of the FOI Act. This condition requires aggressive public sensitisation programmes by civil society organisations to motivate Nigerians to pursue the enforcement of the FOI Act. With aggressive and sustained disposition by members of the Nigerian public, perhaps, the FOI Act could become effective to deliver the social and economic changes which informed its enactment in 2011.

\section{CONCLUSION}

The fervour with which members of the Nigerian public and civil society organisations pursued the passage of the FOI bill into law has not been translated into action several years after the Act was enacted. In fact, the under-utilisation of the FOI Act by members of the public raises the question as to whether they (members of the public) were not aware of the contents of the law whose legislation they enthused. Nigeria, just as other developing countries, has got several socio-political and economic challenges. One of the ways of tackling such challenges is the collaborative effort of an enlightened citizenry. The Freedom of Information Act which empowers citizens of the country to enquire into the day-to-day activities of governments and other institutions would be a strategic asset to achieve the needed transformation which individuals and groups yearn for. Except there becomes the effective enforcement of the FOI Act, the hope for the realisation of the changes which the Act seeks will remain elusive.

\section{RECOMMENDATIONS}

Based on the findings of the study, the following recommendations were considered useful:

1. Civil society organisations should commence nationwide public enlightenment campaigns to sensitise members of the public on the provisions and value of the FOI Act in achieving the sociopolitical and economic changes they desire. Such campaigns should go beyond mere concentration on the mass media. Inter-personal channelsseminars/workshops, round table discussions and conferences across various regions, states and local 
government areas in Nigeria will help to sensitise citizens on the values of the FOI Act.

2. Efforts must be made by relevant agencies to encourage citizens of Nigeria to challenge the refusal of access to official information in court. The FOI Act makes provisions for citizens to seek redress in court when access to official information or records is denied.

3. Members of the public must be willing to make full utilisation of the FOI Act. Citizens must shun lukewarm attitude towards the Act. They (citizens) must embrace the transformation which the FOI Act seeks to achieve. This transformation can only be achieved through aggressive application of the FOI Act by Nigerian citizens.

\section{REFERENCES}

1. Ewelukwa, B. N. (2004). Introduction to Nigerian press law. Onitsha: Varsity Publishing Co. Ltd.

2. Ashong, C. A., \& Udoudo, A. J. (2012). Nigeria's freedom of information act: A case of still birth. Journal of African Communication Research, 5(3):337-356.

3. Griffin, E. M. (2000). A first look at communication theory $\left(4^{\text {th }}\right.$ edition). New York: McGraw Hill Inc.

4. Locke, J. (1988). Locke: Two treatises of government student edition. Cambridge University Press.

5. Bhargava, R., \& Ashok, A. (2008). Political theory: An introduction. New Delhi: Dorling Kindersley Pvt. Ltd.

6. Nwodu, L. C. (2007). Corporate public relations management. Enugu: Precision Publishers Limited.
7. Daramola, I. (2005). Mass media and society. Lagos: Rothan Press Ltd.

8. Johari, J. C. (2006). Contemporary political theory: New dimensions, basic concepts and major trends. New Delhi: Sterling Publishers Private Ltd.

9. Mill, J. S. (1984). On liberty. London: Everyman.

10. Asadu, C. A., \& Usua, N. J. (2011). Fundamentals of international communication. Port Harcourt: University of Port Harcourt Press.

11. UNESCO. (1980). Many voices, one world: Communication and society today and tomorrow. Paris: Kogan Page Limited.

12. Smith, J. (1996). Empowering people. London: Kogan Page Limited.

13. Article 19 (2013). Freedom of information. Retrieved from www.article 19.org, on June 18, 2014.

14. Anyanwu, E. U., Akanwa, P. C., \& Oyemike, V. O. (2013). Freedom of information bill, its relevance and challenges in national development: The Nigerian example. Retrieved from http://digitalcommon.edu/libPhilprac/1030, on June 23, 2014.

15. Federal Republic of Nigeria. (2006). National population and housing census. Abuja: National Population Commission.

16. Keyton, J. (2001). Communication research: Asking questions, finding answers. New York: McGraw Hill Higher Education.

17. Federal Republic of Nigeria. (2011). Freedom of information act. Abuja: Federal Government of Nigeria.

18. Gibson, L. J. (2002). Truth, justice and reconciliation: Judging the fairness of amnesty in South Africa. American Journal of Political Science, 46(3):540-556. 